\title{
Pendayagunaan Guru Sekolah Luar Biasa Idayu Malang dalam Deteksi Dini Gangguan Bicara dan Bahasa pada Anak
}

\author{
Nurdiana $^{1}$, Ni Luh Putu Herli Mastuti ${ }^{1.2}$, Astri Proborini ${ }^{1,2}$, Yuseva Sariati ${ }^{1}$, \\ Nur Aini Retno Hastuti ${ }^{1}$, Miftahul Jannah ${ }^{1}$ \\ Universitas Brawijaya, Malang, Indonesia \\ Rumah Sakit Brawijaya, Malang, Indonesia \\ herlimastuti@ub.ac.id
}

Received: $2^{\text {nd }}$ November 2020 | Accepted: $20^{\text {th }}$ July $2021 \mid$ Published: $27^{\text {th }}$ July 2021

Key word:

teacher;

Special school;

Special needed

children;

speech and

language

\section{Kata Kunci}

Guru;

Sekolah Luar

Biasa;

Anak

Berkebutuhan

Khusus;

Bahasa dan

Bicara

\section{Abstract}

The increase prevalence of speech and language disorders, which greatly affects the quality of life of a child. The role of educational institutions, especially teachers, is needed in early detection of these disorders. Early detection abilities must be based on the ability to understand a child's speech and language development. Community Service Activities are carried out at the Idayu 2 Malang Special School, by providing training to teachers on speech and language development and early detection methods. The method used is the provision of material followed by an examination of the student's status growth ad development. There was an increase in the teacher's ability after the activity was carried out, which was marked by an increase in the average pretest and postest results: 61.15 to 86.54. On examination of the student's growth status, the nutritional status of the majority of students was found to be good nutrition (61\%), but the short stature rate was also quite large $(49 \%)$. The condition of children with special needs with physical limitations greatly affects their growth and development, so that the role of the environment is needed for optimal development, including parents and educational institutions.

\section{Abstrak}

Peningkatan gangguan bicara dan bahasa semakin meningkat, yang sangat mempengaruhi kualitas hidup seorang anak. Peranan lembaga pendidikan terutama guru sangat diperlukan dalam deteksi dini gangguan tersebut. Kemampuan deteksi dini harus didasari dengan kemampuan pemahaman perkembangan bicara dan bahasa seorang anak. Kegiatan Pengabdian Masyarakat dilakukan di Sekolah Luar Biasa Idayu 2 Malang, dengan memberikan pelatihan kepada guru tentang perkembangan bicara dan bahasa serta cara deteksi dini. Metode yang dilakukan adalah pemberian materi yang dilanjutkan pemeriksaan status pertumbuhan dan perkembangan murid. Didapatkan peningkatan kemampuan guru setelah dilakukan kegiatan, yang ditandai dengan peningkatan hasil rata-rata pretest dan postest, yaitu : 61,15 menjadi 86,54. Pada pemeriksaan status pertumbuhan murid, didapatkan Status gizi sebagaian besar murid adalah gizi baik (61\%), tetapi angka perawakan pendek juga cukup besar (49\%). Keadaan ABK dengan keterbatasan fisik sangat mempengaruhi pertumbuhan dan perkembangannya, sehingga diperlukan peranan lingkungan, antara lain orang tua dan Lembaga Pendidikan. 


\section{PENDAHULUAN}

Seorang anak mempunyai ciri-ciri mengalami pertumbuhan dan perkembangan. Perkembangan adalah bertambahnya kemampuan (skil) struktur dan fungsi tubuh yang lebih kompleks, dalam pola yang teratur dan dapat diramalkan, sebagai hasil dari proses pematangan/maturitas. Perkembangan menyangkut proses diferesiansi sel tubuh, jaringan tubuh, organ dan sistem organ yang berkembang sedemikian rupa sehingga masing masing dapat memenuhi fungsinya (Soetjiningsih, 2013). Perkembangan adalah bertambahnya struktur dan fungsi tubuh yang lebih kompleks dalam kemampuan gerak kasar, gerak halus, bahasa serta sosialisasi dan kemandirian. Keempat aspek perkembangan tersebut menjadi perhatian dalam tahap tumbuh kembang anak (Depkes RI, 2007).

Salah satu aspek penting dalam proses perkembangan adalah kemampuan bahasa. Hal ini merupakan indicator seluruh perkembangan anak, karena kemampuan bahasa sensitif terhadap keterlambatan atau kerusakan pada sistem lainnya, sebab melibatkan kemampuan kognitif, motorik, psikologis, emosi dan lingkungan sekitar anak (Santrock. J.W, 2009).
Angka terjadinya keterlambatan perkembangan dalam 12 tahun terakhir mengalami peningkatan. Pada suatu penelitian yang dilakukan di Amerika Serikat menyatakan bahwa dalam 12 tahun terakhir angka kejadian keterlambatan perkembangan meningkat dari 12,84\% menjadi 15,04 \% (Boyle CA, Boulet S, Schieve LA, Cohen RA, Blumberg SJ, Visser S, 2011). Selain itu keterlambatan perkembangan yang terjadi pada tiap populasi berbeda, studi yang dilakukan Dudley menunjukkan bahwa 3,3 - $17 \%$ anak mengalami keterlambatan perkembangan (Dudley L \& Vasche T, 2010). Beberapa penelitian yang dilakukan di Indonesia menunjukkan gangguan perkembangan pada anak mencapai angka $12,6 \%-28,5 \%$ (Sinto, 2008).

Setiap anak mempunyai hak untuk mendapatkan pendidikan, seperti tertuang dalam Undang-Undang RI Nomor 23 Tahun 2002, tentang Perlindungan Anak, pada pasal 9 yang menyebutkan : Setiap anak berhak memperoleh pendidikan dan pengajaran dalam rangka pengembangan pribadinya dan tingkat kecerdasannya sesuai dengan minat dan bakatnya. Pendidikan untuk Anak Berkebutuhan Khusus semakin berkembang, sejalan dengan semakin meningkatnya angka kejadian gangguan pertumbuhan dan perkembangan anak. 
Pendidikan Luar Biasa atau Sekolah Luar Biasa (SLB) merupakan pendidikan bagi peserta didik yang memiliki tingkat kesulitan dalam mengikuti proses pembelajaran karena kelainan fisik, emosional, mental sosial, tetapi memiliki potensi kecerdasan dan bakat istimewa. Dalam Encyclopedia of Disability tentang pendidikan luar biasa dikemukakan sebagai berikut: "Special education means specifically designed instruction to meet the unique needs of a child with disability". Pendidikan luar biasa berarti pembelajaran yang dirancang secara khusus untuk memenuhi kebutuhan yang unik dari anak kelainan fisik (Suparno, 2007).

Berdasarkan keadaan diatas, peranan guru Sekolah Luar Biasa (SLB) sangat penting dalam deteksi dini adanya gangguan perkembangan, terutama gangguan bahasa. kegiatan Pengabdian Masyarakat ini bertujuan untuk meningkatakan kemampuan guru dalam memahami perkembangan bahasa seorang anak, yang tentunya akan meningkatkan kemampuan dalam deteksi dini gangguan bahasa.

\section{METODE}

Kegiatan pengabdian masyarakat ini dilakukan dengan memberikan pelatihan kepada guru SLB Idayu tentang perkembangan bahasa serta deteksi dini gangguan bahasa anak. Sekolah Luar Biasa Idayu merupakan sekolah dengan jenjang Sekolah Dasar, Sekolah Menengah Pertama dan Atas, yang memberikan pendidikan untuk anak berkebutuhan khusus termasuk untuk anak dengan gangguan autism.

$$
\text { Pelaksanaan kegiatan dilakukan }
$$
selama dua hari, dengan melibatkan semua guru dan evaluasi kegiatan dilakukan dengan memberikan pretest dan posttest kegiatan.

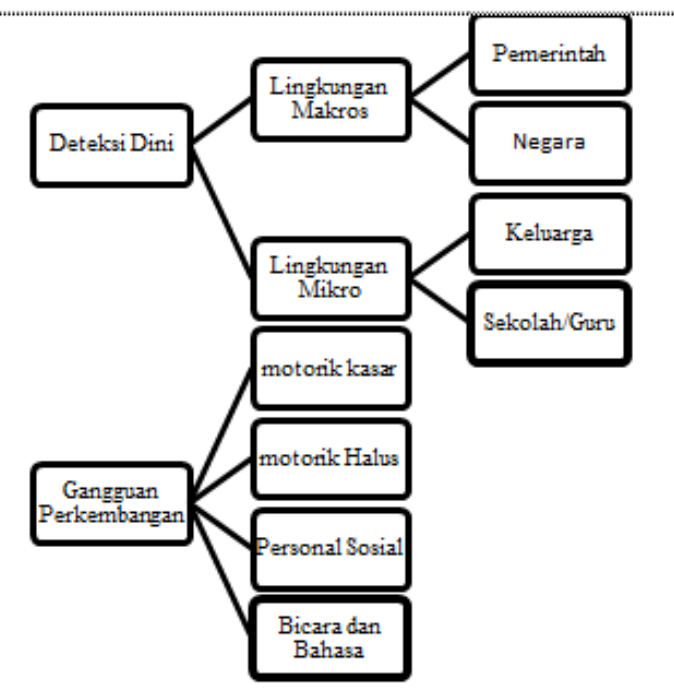

Gambar 1. Kerangka pemecahan masalah deteksi gangguan bahasa anak

\section{HASIL}

$\begin{array}{ccc}\text { Kegiatan } & \text { dilakukan } & \text { dengan } \\ \text { memberikan } & \text { pelatihan } & \text { tentang }\end{array}$
perkembangan bahasa seorang anak, yang diikuti oleh 28 guru. Sebelum kegiatan dilakukan pretest dan postest pada akhir kegiatan, untuk melihat peningkatan kemampuan guru tentang materi yang diberikan. Terdapat peningkatan rata rata 
nilai dari pretest sebesar 61,15 menjadi 86,54 pada saat posttest.

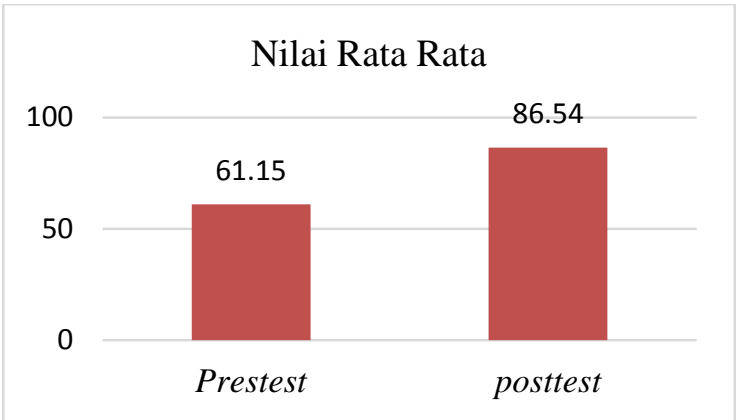

Grafik 1. Nilai rataan pretest dan posttest

Materi yang diberikan adalah tentang perkembangan bicara dan Bahasa pada anak, serta cara mendeteksi gangguan bicara dan Bahasa. Bahasa merupakan suatu bentuk komunikasi, baik secara lisan, tertulis maupun tanda - tanda yang didasarkan pada sebuah simbol - simbol (Santrock. J.W, 2009). Bahasa reseptif adalah kemampuan untuk mengerti, termasuk keterampilan visual (reading, sign language comprehension) dan auditory (listening comprehension). Sedangkan bahasa ekspresif adalah kemampuan untuk memproduksi simbol komunikasi, luaran ini dapat juga berupa visual (writing, signing) atauauditory (speech) (Soetjiningsih, 2013).

Hemisfer kiri merupakan pusat kemampuan berbahasa pada $94 \%$ orang dewasa kanan dan lebih dari $75 \%$ pada orang dewasa kidal. Pengkhususan hemisfer untuk fungsi bahasa sudah dimulai sejak di dalam kandungan, tetapi bagian ini baru berfungsi secara sempurna setelah beberapa tahun kemudian. Terdapat 3 area utama pada hemisfer kiri anak yang khusus untuk berbahasa, yaitu area broca dan kortek motorik di bagian anterior, dan area wernicke di bagian posterior. Informasi yang berasal dari kortek pendengaran primer dan sekunder, diteruskan kebagian kortek temporo parietal posterior (area Wernicke). Informasi ini kemudian dicocokkan dengan ingatan yang sudah disimpan sebelumnya. Jawaban diformulasikan dan disalurkan oleh fasciculus arcuatus kebagian anterior otak, untuk koordinasi jawaban motorik (area Broca). Apabila terjadi kelainan pada salah satu jalan impuls ini, akan terjadi kelainan bicara. Kerusakan pada bagian posterior akan mengakibatkan kelainan bahasa reseptif, sedangkan kerusakan di bagian anterior akan menyebabkan kelainan bahasa ekspresif.

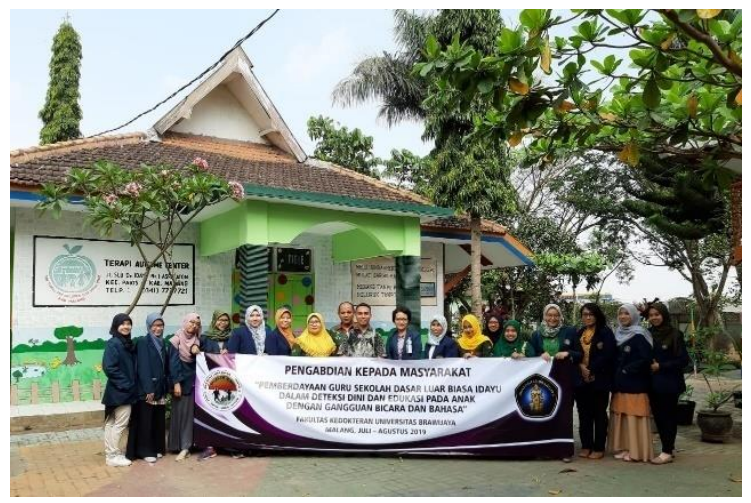

Gambar 2. Pengurus dan Guru SLB Idayu

Kemampuan berbahasa merupakan indikator seluruh perkembangan anak, karena kemampuan berbahasa sensitif 
terhadap keterlambatan atau kelainan pada system lainnya, seperti kemampuan kognitif, sensori motor, psikologis, emosi dan lingkungan di sekitar anak. Rangsangan sensoris yang berasal dari pendengaran (auditory expressive language development and auditory development) receptive language development) dan penglihatan (visual language sangat penting dalam perkembangan bahasa. Menurut teori neuro psikoinguistik, berbahasa adalah interaksi yang kompleks antara fungsi otak (korteksserebri), semantik dan fragmatik, fonologi, grammar dan organ yang memproduksi bahasa. Sistem ini saling berhubungan. Bila salah satu mengalami masalah makaakan terjadi gangguan bicara. Untuk diagnosis gangguan bicara, kita harus mengetahui milestones perkembangan bicara yang normal terlebih dahulu. Kisaran waktu milestones perkembangan bahasa cukup lebar, sehingga membuat klinisi sulit untuk menentukan normal atau tidak (Soetjiningsih, 2013).

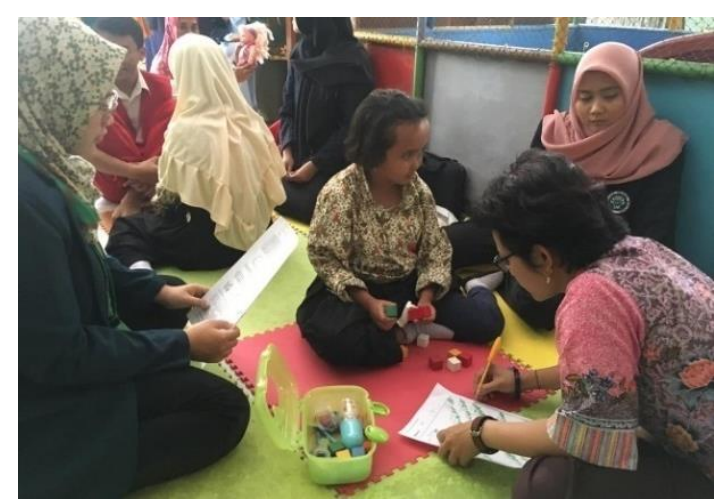

Gambar 3. Kegiatan Pemeriksaan Perkembangan Murid
Pada hari kedua, untuk menerapkan dan melihat pemahaman guru tentang deteksi gangguan Bahasa, dilakukan pemeriksaan pertumbuhan dan perkembangan murid-murid. Pada kegiatan ini, diikuti oleh 44 murid, yang karena keterbatasannya, didampingi oleh orang tua / pendamping.

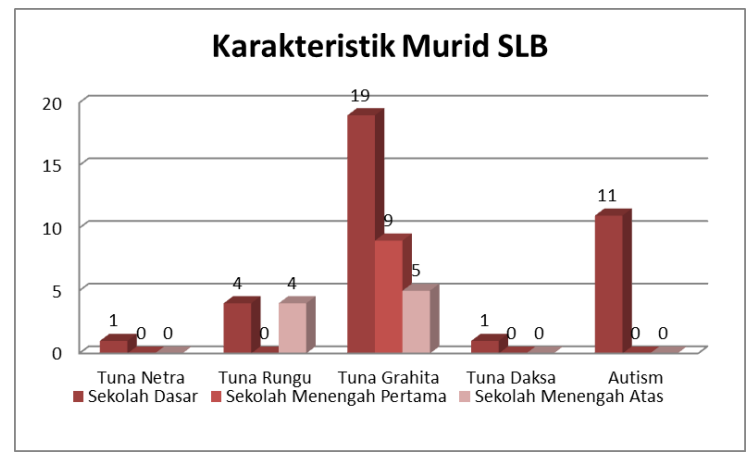

Grafik 2. Karakteristik murid SLB

Pada kegiatan hari kedua ini, guru dilatih untuk melakukan pemeriksaan pertumbuhan dan perkembangan murid. Pemeriksaan dilakukan pada 44 murid, dengan pendampingan orang tua atau guru karena keterbatasan murid. Klasifikasi status pertumbuhan murid berdasarkan berat badan terhadap usia, menjadi gizi kurang, gizi baik, gizi lebih. Sedangkan berdasarkan tinggi badan terhadap usia, menjadi : perawakan pendek, normal, maupun perawakan tinggi. Perkecualian penentuan status gizi pada satu murid, disebakan keterbatasan fisik, didasarkan pada ukuran lingkar lengan atas (Grafik 3) (Kemkes RI, 2016) 


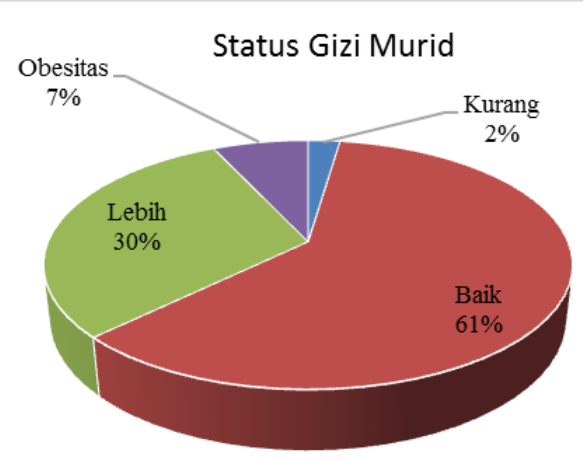

Grafik 3. Status Gizi Murid SLB

Berdasarkan tinggi badan terhadap usia, dilakukan pada 43 murid, satu murid tidak dapat ditentukan karena keterbatasan fisik. Murid-murid SLB Idayu mempunyai perawakan normal (51\%), meskipun tidak berbeda jauh jumlahnya

\section{PEMBAHASAN}

SLB berdasarkan sejarahnya ditujukan untuk peserta didik Anak Berkebutuhan Khusus (ABK) dengan masing-masing kekhususannya. Jenis kekhususan tersebut menjadi landasan pendirian sebuah SLB. SLB di Indonesia dikategorisasikan menjadi beberapa jenis. Adapun kategorisasi 22 SLB berdasarkan kekhususannya menurut UU Sisdiknas No 20/2003 Pasal 32 ayat 1 yaitu : a. SLB bagian A untuk tuna netra b. SLB bagian B untuk tuna rungu c. SLB bagian C untuk tuna grahita $(\mathrm{C}$ untuk tuna grahita ringan dan C1 untuk tuna grahita sedang) d. SLB bagian $\mathrm{D}$ untuk tuna daksa (D untuk tuna daksa ringan dan D1 untuk tuna daksa sedang) e. SLB bagian E untuk tuna laras f.
SLB bagian F untuk autisme g. SLB bagian $\mathrm{G}$ untuk tuna ganda.

Selain itu, Pendidikan anak berkebutuhan khusus dapat dilakukan dengan melakukan pendidikan inklusi. Pendidikan inklusi adalah bentuk penyelenggaraan pendidikan yang menyatukan anak - anak berkebutuhan khusus dengan anak - anak normal pada umumnya untuk belajar. Menurut Hildegun Olsen (Tarmansyah, 2007), pendidikan inklusi adalah sekolah harus mengakomodasi semua anak tanpa memandang kondisi fisik, intelektual, social emosional, linguistik atau kondisi lainnya. Ini harus mencakup anak - anak penyandang cacat, berbakat. Anak - anak jalanan dan pekerjaan berasal dari populasi terpencil atau berpindah - pindah. Anak yang berasal dari populasi etnis minoritas, linguistik, atau budaya dan anak anak dari area atau kelompok yang kurang beruntung atau termajinalisasi. Pendidikan inklusi adalah sebuah pelayanan pendidikan bagi peserta didik yang mempunyai kebutuhan pendidikan khusus di sekolah regular (SD, SMP, SMU, dan SMK) yang tergolong luar biasa baik dalam arti kelainan, lamban belajar maupun berkesulitan belajar lainnya (Lay Marthan, 2007).

Sekolah Luar Biasa Idayu, melayani Pendidikan untuk kategori A (Tuna netra), 
B (Tuna Rungu), C (Tuna Grahita), dan Autism.

Peningkatan kemampuan seseorang dapat dilakukan dengan berbagai model pembelajaran. Model pembelajaran ialah pola yang digunakan sebagai pedoman dalam merencanakan pembelajaran di kelas maupun tutorial, atau dapat didefinisikan sebagai kerangka konseptual yang melukiskan prosedur sistematis dalam mengorganisasikan pengalaman belajar untuk mencapai tujuan belajar (Supriyono, 2012).

Proses pembelajaran pada dasarnya adalah suatu kegiatan komunikasi, yaitu proses penyampaian pesan dari sumber pesan melalui saluran atau media tertentu ke penerima pesan, sumber pesan, saluran atau media dan penerima pesan adalah komponen komponen komunikasi. Banyak metode yang dilakukan untuk pembelajaran, antara lain: Ceramah, Demonstrasi Cara, Demonstrasi Hasil, Diskusi, Kontes / Perlombaan, Magang, Sekolah Lapangan (Wahjuti, 2014).

Angka prevalensi gangguan bicara dan bahasa pada anak semakin meningkat dari 2,3 sampai 19 persen. Gangguan ini akan menimbulkan efek merugikan terhadap kehidupan seorang anak, meskipun telah dilakukan intervensi (Mc Laughin, 2011). Deteksi dini gangguan bicara dan bahasa sulit dilakukan, karena beberapa anggapan bahwa pengaruh genetic lebih berperan dalam perkembangan bicara dan bahasa, missal riwayat keterlambatan pada orang tua. Keadaan ini menjadi latar belakang mengapa sangat penting untuk mengetahui tanda tanda awal gangguan bicara dan bahasa yang diterapkan dalam langkah deteksi dini gangguan perkembangan (Sunderajan, T. Kanhere, 2019).

Kegiatan yang dilakukan, diawali dengan pemberian materi yang dilanjutkan dengan pemeriksaan status pertumbuhan dan perkembangan murid - murid. Terdapat peningkatan kemampuan peserta pelatihan yang ditandai dengan peningkatan nilai rata - rata pretest dan postets peserta (Tabel 1). Hasil ini diharapkan menunjukkan kemampuan peserta untuk melakukan deteksi gangguan bicara dan bahasa pada anak-anak. Selain itu peranan guru bukan hanya deteksi di lingkungan sekolah, tetapi juga di lingkungan guru yang bersangkutan, missal keluarga maupun masyarakat sekitar.

Peranan guru di lingkungan masyarakat sangat besar, terutama di bidang kesehatan dan pendidikan masyarakat. Hal ini menuntut kemampuan guru dalam perkembangan ilmu serta kemampuan melakukan komunikasi. Hargreaves pada tahun 2003 menyebutkan "...Teachers, more than anyone, are 
expected to build learning communities, create the knowledge society, and develop the capacities for innovation, flexibility and commitment to change that are essential to economic prosperity" (Rahardian D, 2015) (Hargreaves, 2003). Hal ini menunjukkan tugas dan peranan penting guru di lingkungan masyarakat umum dan sekolah. Salah satu peran guru adalah sebagai profesional. Jabatan guru sebagai professional menuntut peningkatan kecakapan dan mutu keguruan secara berkesinambungan. Guru yang berkualifikasi profesional, yaitu guru yang tahu secara mendalam tentang apa yang diajarkannya, cakap dalam cara mengajarkannya secara efektif serta efisien, dan guru tersebut punya kepribadian yang mantap. Selain itu integritas diri serta kecakapan keguruannya juga perlu ditumbuhkan serta dikembangkan (Karsidi, 2005).

Guru diharapkan mampu memelihara hubungan dengan masyarakat disekitar sekolahnya maupun masyarakat yang luas untuk kepentingan pendidikan. Hal ini dapat dilakukan dengan: Guru memperluas pengetahuan masyarakat mengenai profesi keguruan, Guru turut menyebarkan program - program pendidikan dan kebudayaan kepada masyarakat sekitarnya, sehingga sekolah tersebut turut berfungsi sebagai pusat pembinaan dan pengembangan pendidikan dan kebudayaan ditempat itu, guru harus berperan agar dirinya dan sekolahnya dapat berfungsi sebagai unsure pembaru bagi kehidupan dan kemajuan daerahnya, guru turut bersama - sama masyarakat sekitarnya di dalam berbagai aktifitas, guru mengusahakan terciptanya kerjasama yang sebaik - bainya antara sekolah, orang tua murid, dan masyarakat bagi kesempurnaan usaha pendidikan atas dasar kesadaran bahwa pendidikan merupakan tangung jawab bersama antara pemerintah, orang tua murid dan masyarakat (Rahardian D, 2015).

Kegiatan yang dilakukan pada hari kedua, menunjukkan bahwa murid di SLB Idayu mempunyai status peetumbuhan dan perkembangan yang berbeda. Penentuan status pertumbuhan dilakukan berdasarkan berat badan, tinggi badan, serta perbandingan berat badan menurut tinggi badan. Status gizi sebagaian besar murid adalah gizi baik (61 \%), tetapi angka perawakan pendek juga cukup besar (49 $\%)$. Perawakan pendek didefinisikan sebagai tinggi badan (TB) kurang dari -2 standar deviasi (SD) atau dibawah persentil ke-3 sesuai jenis kelamin dan usia rata-rata sesuai kurva pertumbuhan yang berlaku pada populasi tersebut (Batubara, JS. Faisal, 2018). 


\section{Menurut RISKESDAS 2018,} dilaporkann bahwa $30,8 \%$ anak balita Indonesia termasuk kategori sangat pendek dan pendek. Sedangkan berdasarkan hasil 2013, sebesar 37,2 \% (Kemenkes, 2018) (Rochmah, N. Faizi,M.Wicaksono, H., Wijani, LAA., Dinatha, BD., Lestari, SR., Choirunisa, 2019).

Beberapa penyebab perawakan pendek baik yang merupakan idiopatik maupun patologis. Penyebab patologis antara lain: defisiensi Hormon Pertumbuhan (Growth Hormone Deficiency), hipotiroid, Sindrom Turner, penyakit hati, ginjal, gastrointestinal, maupun defisiensi nutrisi primer (Rochmah, N. Faizi,M.Wicaksono, H., Wijani, LAA., Dinatha, BD., Lestari, SR., Choirunisa, 2019).

Perawakan pendek yang terjadi pada murid cukup besar, belum dapat ditentukan penyebabnya, karena perlu melakukan pemeriksaan lebih lengkap. Beberapa kemungkinan yang bias menjadi penyebabnya antara lain: defisiensi nutrisi primer maupun terkait beberapa gangguan di hormon, maupun sindrom penyakit tertentu.

Angka kejadian gangguan nutrisi cukup besar, yaitu gizi lebih (30\%) dan obesitas $(7 \%)$. Anak - anak berkebutuhan khusus (ABK) mempunyai risiko besar terjadi gangguan nutrisi, dikarenakan keterbatasan mereka (Gatineau M, 2011). Penelitian yang dilakukan oleh Ayu lestari (2017) di Pelangi Centre Developmental Neuro rehabilitation Ponorogo menunjukkan Hasil penelitian ini menunjukan bahwa kategori status gizi anak berkebutuhan khusus yang berusia 5 17 tahun dalam penelitian ini. Terdapat 24 anak (40 \%) dengan status gizi kurang, serta 32 anak (53\%) dengan status baik, dan terdapat 4 anak (7\%) dengan status gizi gemuk (Lestari, 2017). Penelitian yang dilakukan pada tahun 2016 menunjukkan bahwa anak dengan gangguan perkembangan mempunyai risiko lebih besar untuk terjadi gangguan nutrisi (48,6 $\%)$ (Malone, C. Sharif,F. Glennon-Slattery, 2016).

Keadaan gangguan perkembangan akan sangat mempengaruhi secara langsung maupun tidak langsung terhadap status gizi seorang anak.

\section{SIMPULAN}

Angka kejadian gangguan pertumbuhan dan perkembangan seorang anak semakin meningkat, juga angka kejadian gangguan bicara dan bahasa. Kehadiran dan peranan Lembaga Pendidikan serta guru sangat berperan dalam pemenuhan kebutuhan pendidikan seorang anak, yang mempunyai tujuan akhir pencapaian pertumbuhan dan 
perkembangan optimal seorang anak, meskipun dalam keterbatasan fisik.

\section{SARAN}

Saran yang dapat diberikan untuk keberlanjutan dan kesinambungan kegiatan pengabdian ini adalah agar lembaga pendidikan dalam hal ini SLB Idayu melakukan pengukuran tumbuh kembang kepada murid-murid secara berkala. Selain itu, kegiatan serupa semoga bisa dilaksanakan dan menjadi pendampingan di SLB-SLB lainnya.

\section{UCAPAN TERIMA KASIH}

Penulis mengucapkan terima kasih kepada seluruh pengurus SLB Idayu 2 Malang, dan murid serta orang tua sehingga kegiatan pengabdian masyarakat ini dapat terlaksana, dan memberikan manfaat bagi anak- anak.

\section{DAFTAR PUSTAKA}

Batubara, JS. Faisal, F. (2018). Buku Ajar Endokrinologi Anak 2nd Ed. IDAI.

Boyle CA, Boulet S, Schieve LA, Cohen RA, Blumberg SJ, Visser S, et. al. (2011). Trends in The Prevalence of Developmental Disabilities in US Children, 1997-2008.

Depkes

RI. (2007).

PedomanPelatihanStimulasi,

Deteksi dan Intervensi Dini
TumbuhKembang Anak di Tingkat Pelayanan Kesehatan Dasar (D. B. K. M. Direktorat Bina Kesehatan Anak, Ed.).

Dudley L \& Vasche T. (2010). Vision Therapy For a Patient with Developmental Delay. Journal of Behavioral Optometry.

Gatineau M, dan D. M. (2011). Obesity and Mental Health. Jurnal. Oxford: National Obesity Observatory.

Hargreaves, A. (2003). Teaching in The Knowledge Society (T. C. C. U. N. Y. and L. Teachers College Press, Ed.).

Karsidi, R. (2005). Sosiologi Pendidikan. UNS Press.

Kemenkes. (2018). Riset Kesehatan Dasar Proporsi Status Gizi Sangat Pendek dan Pendek pada Balita Menurut Propinsi. Badan Penelitian dan Pengembangan Kesehatan Kementrian Kesehatan Republik Indonesia.

Kemkes RI. (2016). Pedoman Pelaksanaan Stimulasi, Deteksi dan Intervensi Dini Tumbuh Kembang Anak.

Lay Marthan. (2007). Manajemen Pendidikan Inklusif. DIRJEN DIKTI.

Lestari, A. (2017). Gambaran Status Gizi pada Anak Berkebutuhan Khusus di Pelangi Developmental 
Neurorehibilitation Ponorogo.

Universitas Muhammadiyah

Ponorogo.

Malone, C. Sharif,F. Glennon-Slattery, C. (2016). Growth and Nutritional Risk in Children with Developmental Delay. Ir J Med Sci, 185(4), 839-846.

Mc Laughin, M. (2011). Speech and Language Delay in Children. American Family Physician, 83(10), 1184-1188.

Rahardian D. (2015). Peran Kedudukan Guru dalam Masyarakat. Jurnal Pendidikan Teknologi dan Informasi.

Rochmah, N. Faizi,M.Wicaksono, H., Wijani, LAA., Dinatha, BD., Lestari, SR., Choirunisa, L. (2019). Pendekatan Tata Laksana Perawakan Pendek (Short Stature) pada Anak. Unit Kerja Endokrinologi Anak dan Remaja.

Santrock. J.W. (2009). Masa Perkembangan Anak, Edisi 11. Salemba Humanika.

Sinto. (2008). Penapisan Perkembangan Anak Usia 6 Bulan -3 Tahun dengan Uji Tapis Perkembangan Denver II. Sari Pediatri, 9 No. 5, 348-369.

Soetjiningsih. (2013). Tumbuh Kembang Anak., Edisi 2. EGC.
Sunderajan, T. Kanhere, S. (2019). Speech and Language Delay in Children: Prevalence and Risk Factors. Journal of Family Medicine and Primary Care, 8(5), 1642-1646.

Suparno. (2007). Pendidikan Anak Berkebutuhan Khusus. Dirjen Dikti Depdiknas.

Supriyono, A. (2012). Cooperative LearningTeori Dan Aplikasi Paikem. Pustaka Pelajar.

Tarmansyah. (2007). Inklusi Pendidikan Untuk Semua. Depdiknas.

Wahjuti. (2014). Metode dan Teknik Penyuluhan Pertanian. Universitas Terbuka. 